\title{
Article
}

\section{The Rac GEF ZizB regulates development, cell motility and cytokinesis in Dictyostelium}

Pakes, N. K., Veltman, D. M., Rivero, F., Nasir, Jamal, Insall, R. and Williams, R. S. B.

Available at https://clok.uclan.ac.uk/18268/

Pakes, N. K., Veltman, D. M., Rivero, F., Nasir, Jamal, Insall, R. and Williams, R. S. B. (2012) The Rac GEF ZizB regulates development, cell motility and cytokinesis in Dictyostelium. Journal of Cell Science, 125 (10). pp. 2457-2465. ISSN 0021-9533

It is advisable to refer to the publisher's version if you intend to cite from the work. http://dx.doi.org/10.1242/jcs.100966

For more information about UCLan's research in this area go to http://www.uclan.ac.uk/researchgroups/ and search for <name of research Group>.

For information about Research generally at UCLan please go to http://www.uclan.ac.uk/research/

All outputs in CLoK are protected by Intellectual Property Rights law, including Copyright law. Copyright, IPR and Moral Rights for the works on this site are retained by the individual authors and/or other copyright owners. Terms and conditions for use of this material are defined in the policies page.

\section{CLoK}

Central Lancashire online Knowledge www.clok.uclan.ac.uk

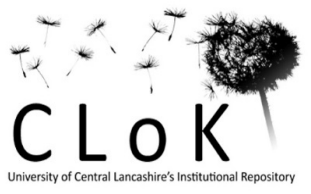




\title{
The Rac GEF ZizB regulates development, cell motility and cytokinesis in Dictyostelium
}

\author{
Nicholl K. Pakes ${ }^{1, \star}$, Douwe M. Veltman ${ }^{2, \star}$, Francisco Rivero ${ }^{3}$, Jamal Nasir ${ }^{4}$, Robert Insall ${ }^{2}$ and \\ Robin S. B. Williams ${ }^{1, \pm}$ \\ ${ }^{1}$ Centre for Biomedical Sciences, School of Biological Sciences, Royal Holloway University of London, Egham, Surrey TW20 0EX, UK \\ ${ }^{2}$ Beatson Institute for Cancer Research, Glasgow G61 1BD, UK \\ ${ }^{3}$ Centre for Cardiovascular and Metabolic Research, Hull York Medical School and Department of Biological Sciences, University of Hull, \\ Hull HU6 7RX, UK \\ ${ }^{4}$ St Georges University of London, London SW17 ORE, UK \\ ${ }^{*}$ These authors contributed equally to this work \\ ${ }^{\ddagger}$ Author for correspondence (robin.williams@rhul.ac.uk) \\ Accepted 25 January 2012 \\ Journal of Cell Science 125, 2457-2465 \\ (c) 2012. Published by The Company of Biologists Ltd \\ doi: 10.1242/jcs. 100966
}

\section{Summary}

Dock (dedicator of cytokinesis) proteins represent a family of guanine nucleotide exchange factors (GEFs) that include the well-studied Dock180 family and the poorly characterised zizimin family. Our current understanding of Dock180 function is that it regulates Rho small GTPases and thus has a role in a number of cell processes, including cell migration, development and division. Here, we use a tractable model for cell motility research, Dictyostelium discoideum, to help elucidate the role of the related zizimin proteins. We show that gene ablation of $z i z A$ causes no change in development, whereas ablation of zizB gives rise to an aberrant developmental morphology and a reduction in cell directionality and velocity, and altered cell shape. Fluorescently labelled ZizA protein associates with the microtubule-organising centre (MTOC), whereas ZizB is enriched in the cortex. Overexpression of ZizB also causes an increase in the number of filopodia and a partial inhibition of cytokinesis. Analysis of ZizB protein binding partners shows that it interacts with Rac1a and a range of actin-associated proteins. In conclusion, our work provides insight into the molecular and cellular functions of zizimin GEF proteins, which are shown to have a role in cell movement, filopodia formation and cytokinesis.

Key words: Chemotaxis, D. discoideum, Dock protein, Rac GEF, Zizimin

\section{Introduction}

The Rho family of small GTPases (Rho, Rac and Cdc42) act as small molecular switches during cellular signalling, where they cycle between an active and an inactive state. These small G proteins are involved in the regulation of many processes within the cell, such as cytoskeletal organisation, cytokinesis, cell morphogenesis, cell migration and development (Dumontier et al., 2000; Jaffe and Hall, 2005; Kolsch et al., 2008; Mondal et al., 2007; Para et al., 2009). The activity of these small GTPases is regulated by the exchange of GDP and GTP, catalysed by guanine nucleotide exchange factors (GEFs), GTPase-activating proteins (GAPs) and guanine nucleotide dissociation inhibitors (GDIs) (Jaffe and Hall, 2005). GEFs regulate GTPases by facilitating the dissociation of GDP, allowing GTP to bind and activate the protein. There are two main families of GEFs for Rho GTPases, the conventional Dbl homology, pleckstrin homology (DH-PH) domain GEFs and the dedicator of cytokinesis (Dock) GEFs (Côté et al., 2005; Côté and Vuori, 2002; Meller et al., 2005). The role of Dock proteins remains a high research priority, because the Dock signalling pathway has been implicated in a number of diseases such as lung cancer and immunodeficiency diseases (Engelhardt et al., 2009; Ruusala and Aspenström, 2004; Takahashi et al., 2006; Zhang et al., 2009).

This is an Open Access article distributed under the terms of the Creative Commons Attribution Non-Commercial Share Alike License (http://creativecommons.org/licenses/by-nc-sa/3.0/), which permits unrestricted non-commercial use, distribution and reproduction in any medium which permits unrestricted non-commercial use, distribution and reproduction in any medium
provided that the original work is properly cited and all further distributions of the work or adaptation are subject to the same Creative Commons License terms.
Mammalian Dock proteins can be subdivided into four main classes: Dock180-related, Dock4-related, zizimin and ziziminrelated (Côté and Vuori, 2002). The Dock proteins are composed of two main domains, the Dock-homology region 1 (DHR1) and the Dock-homology region 2 (DHR2) domains. The DHR1 domain has been shown to bind phospholipids (Côté et al., 2005; Kobayashi et al., 2001; Para et al., 2009). The DHR2 domain interacts with the target GTPase and is responsible for the GEF activity (Brugnera et al., 2002; Côté and Vuori, 2002; Côté and Vuori, 2006). With regard to target specificity, the zizimin and zizimin-related Dock family subgroups have been shown to have a preference for Rac and Cdc42 (Meller et al., 2002).

Eight Dock proteins have been identified in D. discoideum: four Dock180- or Dock4-related (DocA-DocD) and four zizimin or zizimin-related (ZizA-ZizD) proteins. The D. discoideum Dock180-related proteins, DocA and DocD regulate the actin cytoskeleton and cell motility (Para et al., 2009). In our study, we explore the role of the highest expressing $D$. discoideum zizimins, ZizA and ZizB and show both novel and conserved functions of these members of the ancient zizimin protein family.

\section{Results}

Evolutionary conservation, domain characterisation and expression analysis of zizimin proteins

Eight Dock family proteins were identified within the $D$. discoideum genome using homology screening. Phylogenetic analysis of these proteins showed that they comprise four 
zizimin-related proteins (ZizA-ZizD), and four Doc proteins (DocA-DocD) that are homologous to the Dock180-related clade (Fig. 1A). This division into either Dock- or zizimin-type homologues is supported by bootstrap analysis, confirming the early separation of these proteins. The four $D$. discoideum zizimin-related proteins have DHR1 and DHR2 domains and show greatest sequence similarity to the human zizimin-related proteins (Dock6-Dock8) (Fig. 1B), with the human Dock7 being the closest homologue to $D$. discoideum ZizA (36\% identity and $57 \%$ similarity), and human Dock8 being the closest homologue to $D$. discoideum ZizB (28\% identity and $49 \%$ similarity). Comparison of the full-length $D$. discoideum ZizA and ZizB proteins shows a $26 \%$ identity and $44 \%$ similarity (Fig. 1C), where the DHR2 domain (the putative GTPase interacting domain) shows highest homology, with slightly reduced homology in the DHR1 (the putative phospholipid binding domain) and the interdomain region, and low homology in the Nterminal region. The domain structure of these zizimin proteins supports a similarity of function with zizimin-related proteins, rather than human Dock180 proteins that have an additional SH3 domain.
Because the Rho family of small GTPases are known to play a role in development and cell motility (Zigmond et al., 1997), and these processes are often controlled by regulated gene expression (Loomis and Shaulsky, 2011), we examined the expression of $D$. discoideum zizA-zizD over the 24 hour developmental cycle. In these experiments, wild-type cells were developed on a nitrocellulose filter, from which RNA samples were prepared at 4 hour time intervals (Fig. 2). Analysis of the transcription level of $z i z A-z i z D$ by reverse-transcription (RT)-PCR showed that all four genes were expressed throughout growth and development. zizB has the highest expression level, in agreement with the RNA sequence profiling resource (http://dictyexpress.biolab.si/), where mRNA levels are shown to peak at an average of 30 copies per cell during development, which puts it within the top 5\% of the most highly expressed genes (Parikh et al., 2010; Rot et al., 2009). Because the D. discoideum $\mathrm{ZizA}$ and $\mathrm{ZizB}$ proteins grouped within the zizimin or zizimin-related clade of the phylogenetic tree have greatest homology to human Dock7 and Dock8 (which share a similar domain structure) and have the highest expression levels of the four $D$. discoideum zizimins, these two were chosen for further investigation. The $z i z A$ and $z i z B$

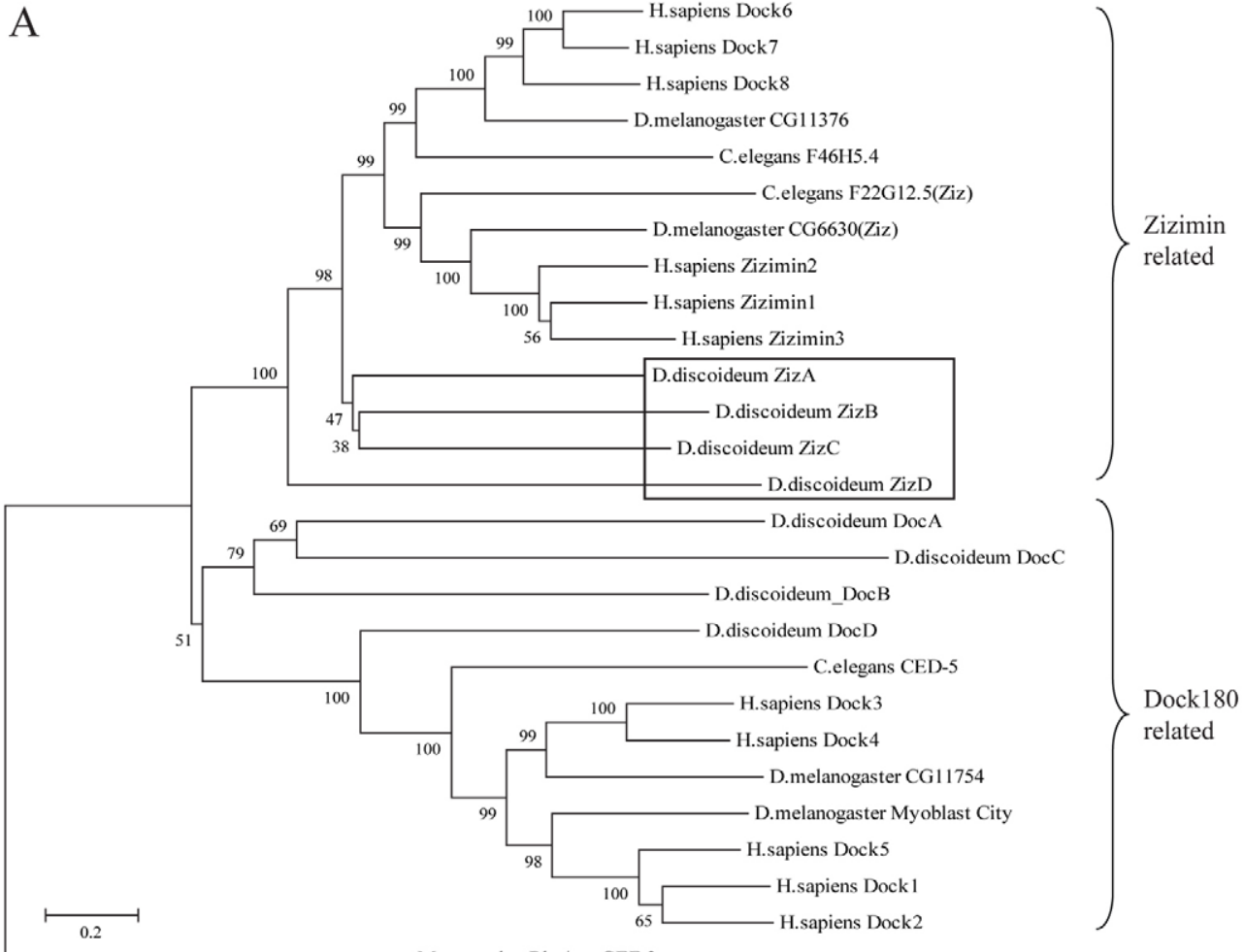

B

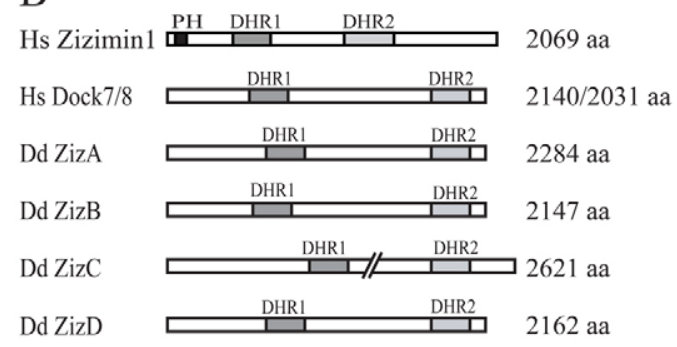

Fig. 1. Phylogenetic and domain structure analysis of the Dock family of proteins. (A) Phylogenetic tree comparing the evolutionary conservation of the $D$. discoideum Dock proteins against Dock proteins from other species. All analysis was performed using Mega5 software. The evolutionary distance was inferred using the neighbour joining method. The percentages of replicate trees in which the associated taxa clustered together in the bootstrap test (500 replicates) are shown next to the branches. The box illustrates the $D$. discoideum ZizAZizD. (B) Schematic of the $D$. discoideum zizimin domain structures compared with the human ziziminrelated proteins (Dock7 and Dock8). (C) Table of the identities and similarities of the ZizA and ZizB DHR1 and DHR2 domains, the intervening sequences $(\mathrm{N}$-terminal intervening sequence and the middle intervening sequence) and the complete protein. 
A

Time (Hr)
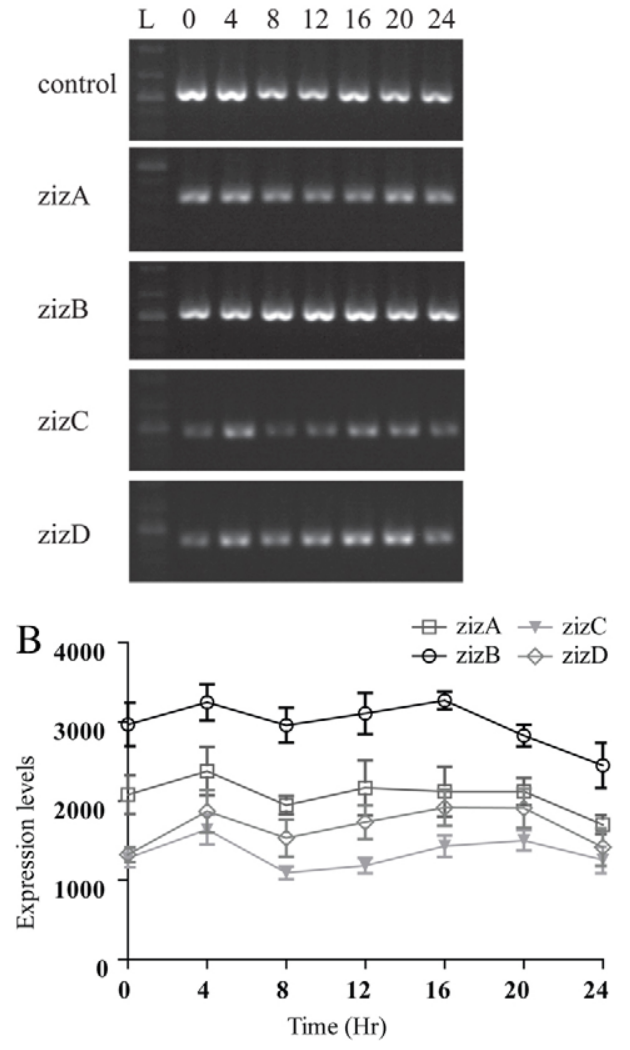

Fig. 2. D. discoideum zizimin gene expression throughout development. RNA samples were prepared from $D$. discoideum cells during growth ( 0 hours) or at 4 hour intervals during development, with derived cDNA used to amplify specific zizimin genes. Lane $\mathrm{L}$ contains the $1 \mathrm{~kb}$ ladder used as a molecular size marker. (A) Agarose gel electrophoresis of $z i z A-z i z D$ cDNAderived PCR products throughout $D$. discoideum development. $\operatorname{Ig} 7$ was used as an expression control. (B) Quantification of the expression levels of $z i z A-$ $z i z D$ from three independent samples.

genes were disrupted by homologous integration of a knockout cassette in several independent cell lines (supplementary material Fig. S1; $z i z A^{-}$and $z i z B^{-}$). Gene disruptions were confirmed by PCR analysis and subsequent loss of gene expression by RT-PCR (supplementary material Fig. S1).

\section{ZizB has a role in development and cell migration}

During development in D. discoideum, cells release chemoattractant cAMP, to which surrounding cells migrate, initiating the formation of a multicellular fruiting body (Schaap and Wang, 1986). We analysed development of cells following both ablation and overexpression of $z i z A$ and $z i z B$ genes at various stages throughout the developmental cycle $(8,13$ and 24 hours) (Fig. 3). A highly active constitutive promoter (Actin6) was used to express each full-length cDNA-derived open reading frame linked to a $\mathrm{C}$-terminal green fluorescent tag (to create ZizA-GFP and ZizB-GFP expression constructs). Cells lacking ZizA protein, or overexpressing either tagged protein in wildtype cells (to form $z i z A^{+}$and $z i z B^{+}$cells) did not show altered development, thus producing mounds at 8 hours and developing to a first-finger stage at 13 hours, then mature fruiting bodies with morphology similar to that of wild-type cells at 24 hours. By contrast, cells lacking the ZizB protein were slightly delayed in

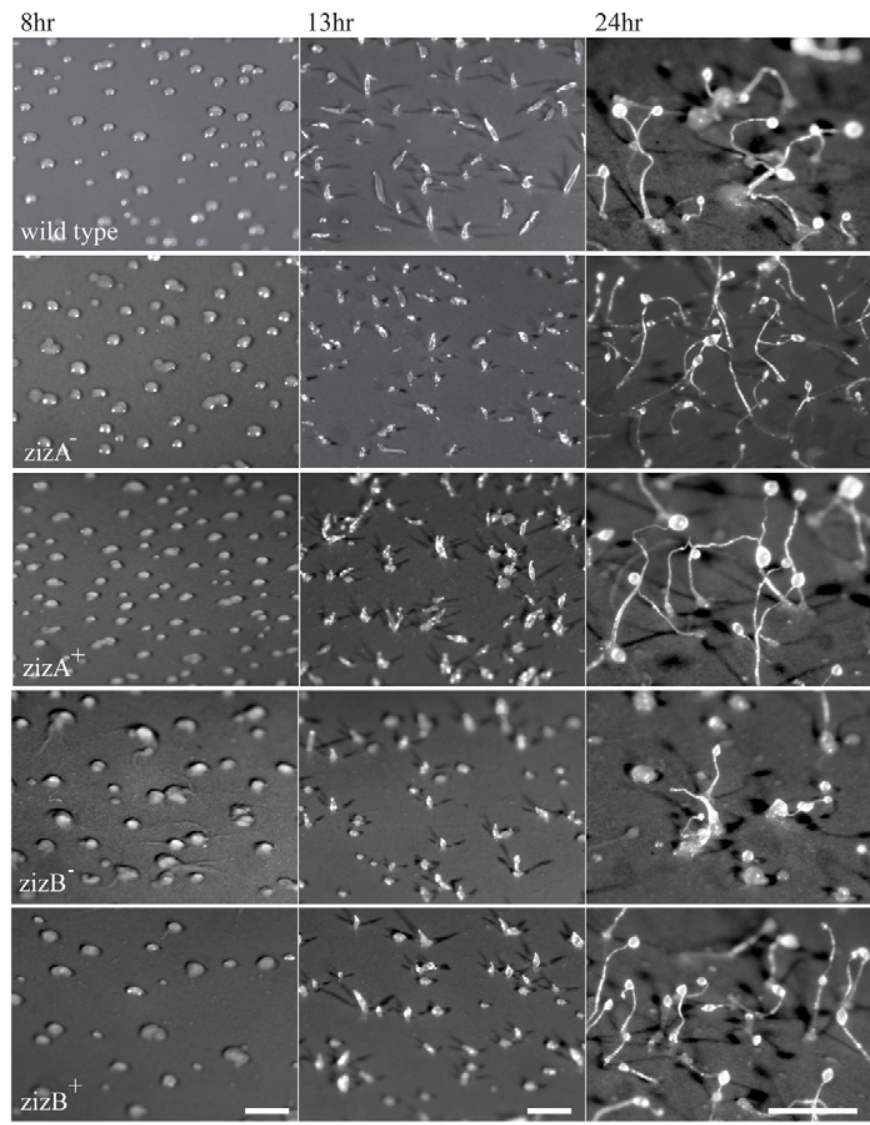

Fig. 3. Development of ZizA- and ZizB-null and overexpressor cells. Wild-type (Ax2), $z i z A^{-}, z i z A^{+}, z i z B^{-}$and $z i z B^{+}$cells were developed on nitrocellulose filters over 24 hours. Fruiting body morphology was recorded at 8,13 and 24 hours from a side angle perspective. The $z i z A^{-}, z i z A^{+}$and $z i z B^{+}$ cells all developed into mature fruiting bodies, comprising a stalk elevating a spore head off the substratum and did not show any defects in early development compared with wild-type cells. However, the $z i z B^{-}$mutant developed aberrant fruiting bodies with thickened, often horizontal stalks and showed a delay in development. Scale bars: $1 \mathrm{~mm}$.

early development compared with wild-type cells (still showing late streaming) at 8 hours, and were again delayed at first-finger stage (13 hours) compared with wild-type cell development. Finally, the $z i z B$-null cells showed sparse collapsed fruiting bodies with thickened stalks in comparison with wild-type cells at 24 hours (Fig. 3). We confirmed this aberrant morphology was caused by gene ablation of $z i z B$ because overexpression of ZizBGFP in $z i z B^{-}$cells (producing $z i z B^{+/-}$cells) rescued aberrant fruiting body morphology.

During the formation of fruiting bodies, the movement of individual cells both towards the chemoattractant cAMP and within an immature fruiting body are necessary to enable these structures to be formed (Schaap and Wang, 1986). To identify whether the developmental defect exhibited by the $z i z B^{-}$cells was due to a cell motility defect, we investigated the ability of the $z i z B^{-}$and $z i z B^{+}$cells to chemotax along a cAMP gradient (Fig. 4). In these experiments, we forced cells to a common developmental point by pulsing with cAMP for 5 hours before chemotaxis analysis. These cells were analysed using time-lapse imaging to record the tracks of single cells during chemotaxis in a shallow cAMP gradient (Dunn chamber). Analysis of migration 
A
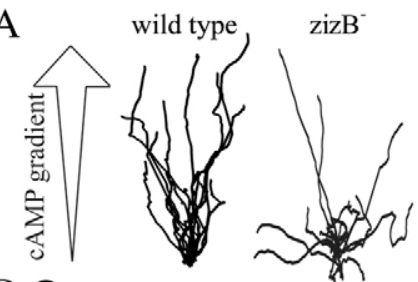

$\mathrm{B}$
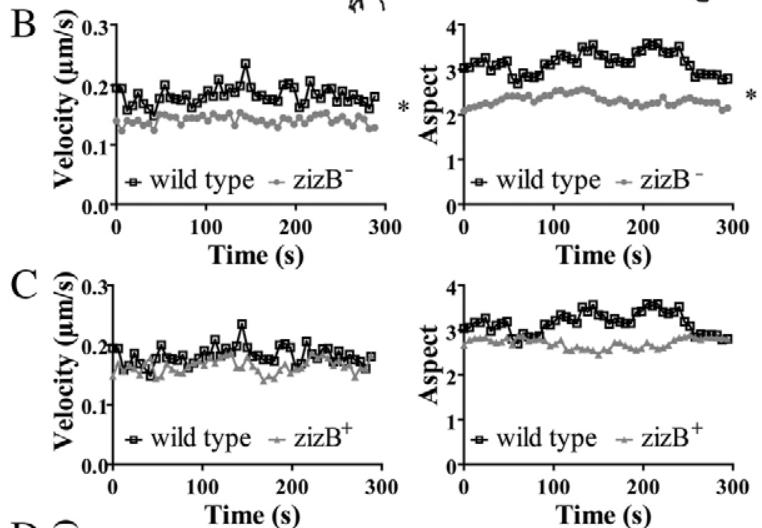

$\mathrm{D}$
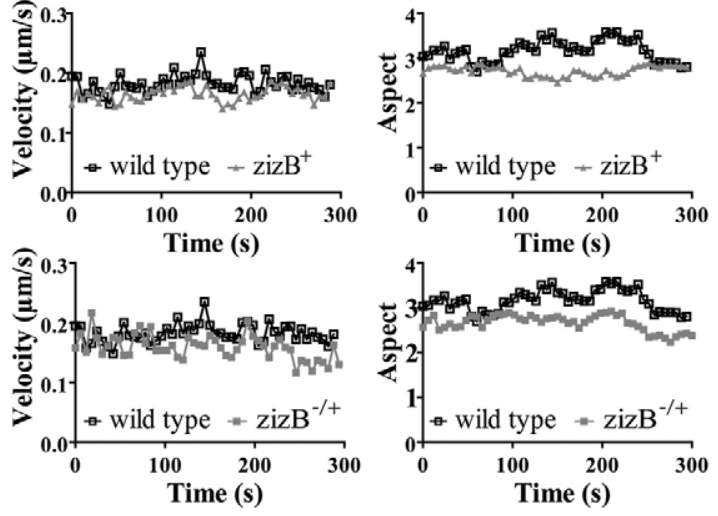

E

\begin{tabular}{|l|c|c|}
\hline & Velocity $(\boldsymbol{\mu m} / \mathbf{m i n})$ & Aspect \\
\hline wild type & $10.92 \pm 0.12$ & $3.16 \pm 0.03$ \\
\hline zizB $^{-}$ & $8.46 \pm 0.42 *$ & $2.32 \pm 0.012 \quad *$ \\
\hline zizB $^{+}$ & $9.84 \pm 0.72$ & $2.71 \pm 0.112$ \\
\hline zizB $^{-/+}$ & $9.54 \pm 0.18$ & $2.66 \pm 0.025$ \\
\hline
\end{tabular}

Fig. 4. Chemotactic effects of ZizB-null and overexpressor cell lines where cells overexpress ZizB-GFP. Cell movement for wild-type, $z i z A^{-}$ and $z i z B^{-}$mutants was recorded by time lapse photography over a 5 minute period (at 6 second intervals) in a Dunn Chamber. Computer-generated cell outlines using Image Pro6.3 software enabled recording of individual cell movement over this period, illustrated here by $X-Y$ coordinate plots. (A) $X-Y$ coordinate plots (directionality) of the $z i z B^{-}, z i z B^{+}$and $z i z B^{-/+}$cells compared with wild-type Ax2 cells. Each line represents the track of a single cell chemotaxing towards cAMP $(5 \mu \mathrm{M})$. (B-D) Analysis of the velocity $(\mu \mathrm{m} /$ s) and aspect (roundness) of the $z i z B^{-}, z i z B^{+}$and $z i z B^{-/+}$cells (grey), respectively, compared with wild-type Ax2 cells (black). (E) Quantitative analysis of cell migration. Aspect refers to the shape of the cell; a perfectly round cell will have an aspect of 1 , whereas a more elongated polarized cell will have a number greater than 1 . Statistical analysis was performed using a Student's $t$-test. All experiments were performed at least in triplicate with an average of $20-30$ cells analysed per experiment. ${ }^{*} P<0.05$.

towards cAMP was used as a measure of cell directionality, illustrated by the $X-Y$ coordinate plots (Fig. 4A). Each line represents the track of a single cell over a 5 minute period. In this assay, the $z i z B^{-}$mutant showed a strong reduction in the ability to move along the chemotactic gradient (supplementary material Movies 1,2), in addition to a significant reduction in cell velocity $(P<0.05$; Fig. 4A,B,E). By contrast, ZizB-GFP overexpression in a wild-type background did not grossly alter cellular movement during chemotaxis compared with wild-type cells (Fig. 4C,E), but reversed the chemotactic deficits shown following loss of ZizB (Fig. 4A,D,E). In addition, analysis of cell shape (aspect) from wild-type, $z i z B^{-}, z i z B^{+}$and $z i z B^{-/+}$cells showed that the $z i z B^{-}$mutant had a more rounded cell shape during chemotaxis (represented by a reduced ratio of cell length to breadth) (Fig. 4B-E). This phenotype was reversed upon overexpression of $z i z B$. These results confirm a role of ZizB in development and chemotaxis in $D$. discoideum, and show that ZizB-GFP can catalyse the cellular events carried out by the endogenous ZizB in D. discoideum.

\section{Overexpression of ZizB produces increased filopodia and a cytokinesis defect}

Cellular localisation of both zizimin proteins was then examined using GFP-tagged proteins by live-cell imaging. ZizA-GFP was distributed throughout the cytosol (Fig. 5A), with enrichment in a structure resembling the microtubule organising centre (MTOC, white arrow) adjacent to the nucleus (supplementary material Movie 5). This localisation of ZizA at the MTOC was confirmed
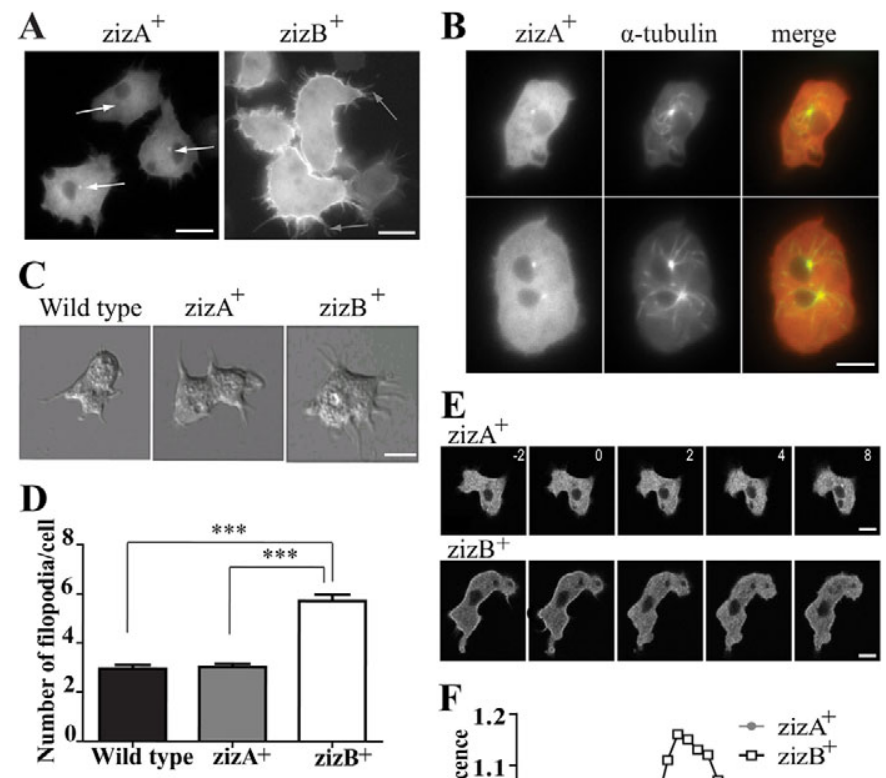

$\mathbf{E}$

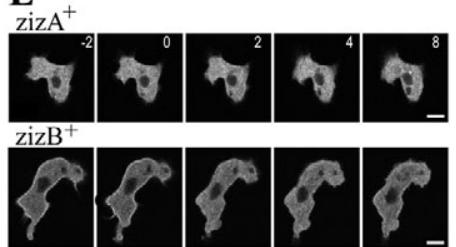

$\mathbf{F}$

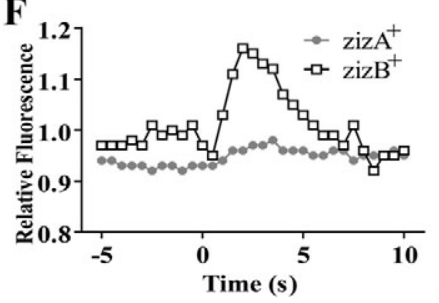

Fig. 5. Cellular localisation and filopodia induction of ZizA-GFP and ZizB-GFP proteins. (A) Live-cell fluorescent imaging of $z i z A^{+}$cells showing ZizA-GFP localisation to the cytosol and a small region associated with the nucleus (indicated by the white arrows), and $z i z B^{+}$cells showing ZizB-GFP localisation to the cytosol with enrichment at the cortex. The $z i z B^{+}$ cells also show an increase in filopodia formation, indicated by the grey arrows. (B) Live-cell fluorescent imaging of ZizA-RFP colocalised with $\alpha$ tubulin-GFP at the MTOC in a mononucleated and dinucleated cell. (C) DIC images illustrate filopodia in wild-type, $z i z A^{+}$and $z i z B^{+}$cells.

(D) Quantification of filopodia/cell for wild-type, $z i z A^{+}$and $z i z B^{+}$cells, time lapse images were analysed (averaging 27 cells) and compared using an unpaired, two-tailed Student's $t$-test $(* * * P<0.0001)$. (E) Time-lapse images of $z i z A^{+}$and $z i z B^{+}$cells following global stimulation with $1 \mu \mathrm{M}$ cAMP, with time points indicating seconds after cAMP addition. (F) Quantification of relative fluorescent levels within the cytosol in $z i z A^{+}$and $z i z B^{+}$cells. Scale bars: $10 \mu \mathrm{m}$. 
by expression of ZizA-RFP in cells containing $\alpha$-tubulin-GFP, where live-cell fluorescence showed colocalisation (Fig. 5B). By contrast, ZizB-GFP was enriched at the cortex (Fig. 5A). The $z i z B^{+}$cells also showed a significant twofold increase in filopodia formation compared with wild-type and $z i z A^{+}$cells $(P<0.0001)$ (Fig. 5A,C,D). The D. discoideum Dock180-related Dock A and Dock D proteins have been previously shown to rapidly translocate to the cell cortex upon global stimulation with cAMP (Para et al., 2009). We investigated whether the $D$. discoideum zizimin proteins are also involved in the chemotactic signalling response. Time-lapse images of cells following a single $1 \mu \mathrm{M}$ cAMP pulse show no change in ZizA-GFP localisation (Fig. 5E,F). Unexpectedly, ZizB-GFP had a different localisation pattern to the $D$. discoideum Dock proteins. Stimulation with cAMP led to its transient removal from the cortex to the cytosol, and then it was returned to the cortex 8 seconds after stimulation (Fig. 5E,F).

We next used live-cell imaging to investigate the localisation of both proteins during cell motility, within a cAMP gradient and during random cell movement. In these experiments, ZizA-GFP showed no change in localisation during either chemotaxis or random movement (supplementary material Movies 3, 5). However, ZizB-GFP was excluded from the trailing edge in both conditions, and appeared enriched in the cortex at the front and sides of the cell (Fig. 6A-C; supplementary material Movies $4,6)$. These data support a role for ZizB in general cell motility (rather than chemotaxis) with a potential cortical function.

Because Dock proteins have been widely associated with a role in cytokinesis, we also examined this process in $z i z A^{-}, z i z B^{-}$, $z i z A^{+}$and $z i z B^{+}$cells by extended (5 day) growth in shaking suspension. These growth conditions eliminated tractionmediated cytokinesis, giving rise to an increase in average cell nuclei number associated with cytokinesis effects. Under these conditions, $z i z B^{+}$cells were commonly unable to complete cell division where the cytoplasmic bridge between dividing cells was not cleaved during cytokinesis to form daughter cells (Fig. 7A,B) unlike wild-type, $z i z A^{-}, z i z B^{-}$or $z i z A^{+}$cells. Visualisation of nuclei number per cell using DAPI staining (Fig. 7C-H) showed a significant $(P>0.05)$ increase in the number of nuclei in $z i z B^{+}$ cells compared with wild-type and $z i z A^{+}$cells (Fig. 7I). This increase was associated with an increase in cell size, and both these effects are consistent with a partial inhibition of cytokinesis in $z i z B^{+}$cells. A decrease in growth rate was only seen in $z i z B^{-}$ cells; however, overexpression of ZizB protein resulted in a highly significant decrease in cell density in the stationary phase $(P<0.0001)$

\section{ZizB interacts with Rac1a}

To further examine the cellular mechanisms of ZizB, we then sought to identify potential binding partners. In this approach, lysates from $z i z B^{+}$cells were immunoprecipitated with anti-GFPantibody-coated beads, and coimmunoprecipitated proteins were visualised by Coomassie Blue staining to identify interacting proteins. Mass spectrometry analysis of unique bands was then used to identify these interacting proteins (Fig. 8; supplementary material Table S1). This approach showed that ZizB bound a range of actin- and/or myosin-associated proteins, including the tubulins TubA and TubB (Triviños-Lagos et al., 1993) (supplementary material Table S1), which is consistent with a role in controlling cortical function and cell movement (Rivero and Somesh, 2002). In addition, ZizB interacted with Racla, a
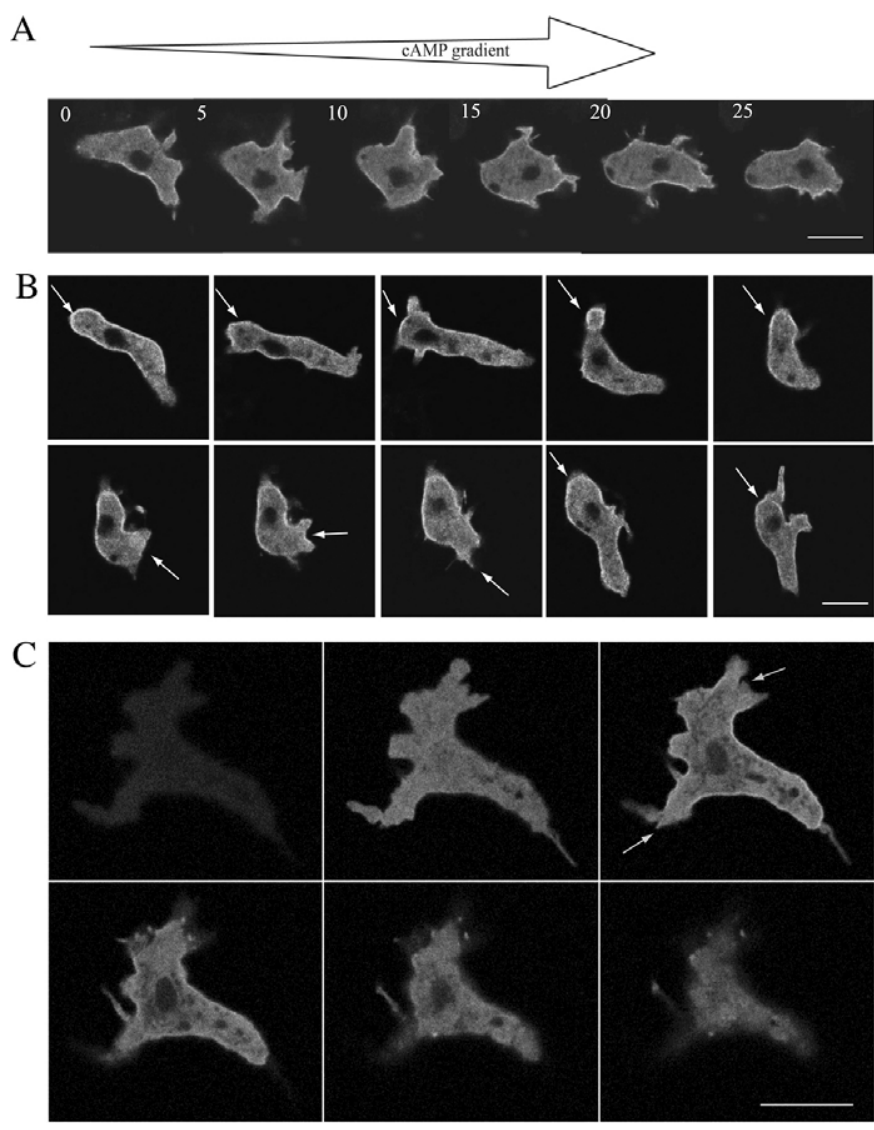

Fig. 6. Localisation of ZizB-GFP protein during chemotaxis and random cell motility. (A) $z i z B^{+}$cells were used in live-cell time-lapse imaging experiments during chemotaxis towards cAMP (time indicated in seconds and the large arrow represents the direction of the cAMP gradient) and (B) during random cell motility (arrows indicate the front of the moving cell). ZizB-GFP increased cortical association towards the front and sides of the cell with a reduction in cortical localisation at the trailing end. $(\mathbf{C})$ The absence of ZizBGFP in the trailing end is confirmed in $3 \mathrm{D}$ reconstruction of $z i z \mathrm{~B}^{+}$cells during random cell motility where retracting pseudopods (grey arrow) lack ZizBGFP cortical localisation. Scale bars: $10 \mu \mathrm{m}$.

small GTPase, formin A, a protein that functions as an actin filament nucleator (Kitayama and Uyeda, 2003), Cap32 and Cap34, which are capping protein subunits (Schleicher et al., 1984; Eddy et al., 1997; Hug et al., 1995) and the ArpC1 and ArpC2 proteins (encoded by $\operatorname{arc} A$ and $\operatorname{arcB}$ ) which form part of the Arp2/3 complex (Langridge and Kay, 2007). These potential binding partners position ZizB in a central role in actin cytoskeletal organisation. To confirm the ZizB interaction with Rac1a, ZizB-GFP protein was washed through a column containing bound (bacterially produced) Rac GST proteins. The protein complex was separated on a SDS-PAGE gel and visualised by western blot analysis (supplementary material Fig. S2). This approach confirmed a direct binding of ZizB to Racla, and also showed an interaction with RacA, RacC and RacG.

\section{Discussion}

ZizB is essential for normal development and cell migration D. discoideum contains four zizimin GEF proteins, with all four containing the characteristic DHR1 and DHR2 catalytic domains associated with the Dock family of proteins (Fig. 1). Expression 

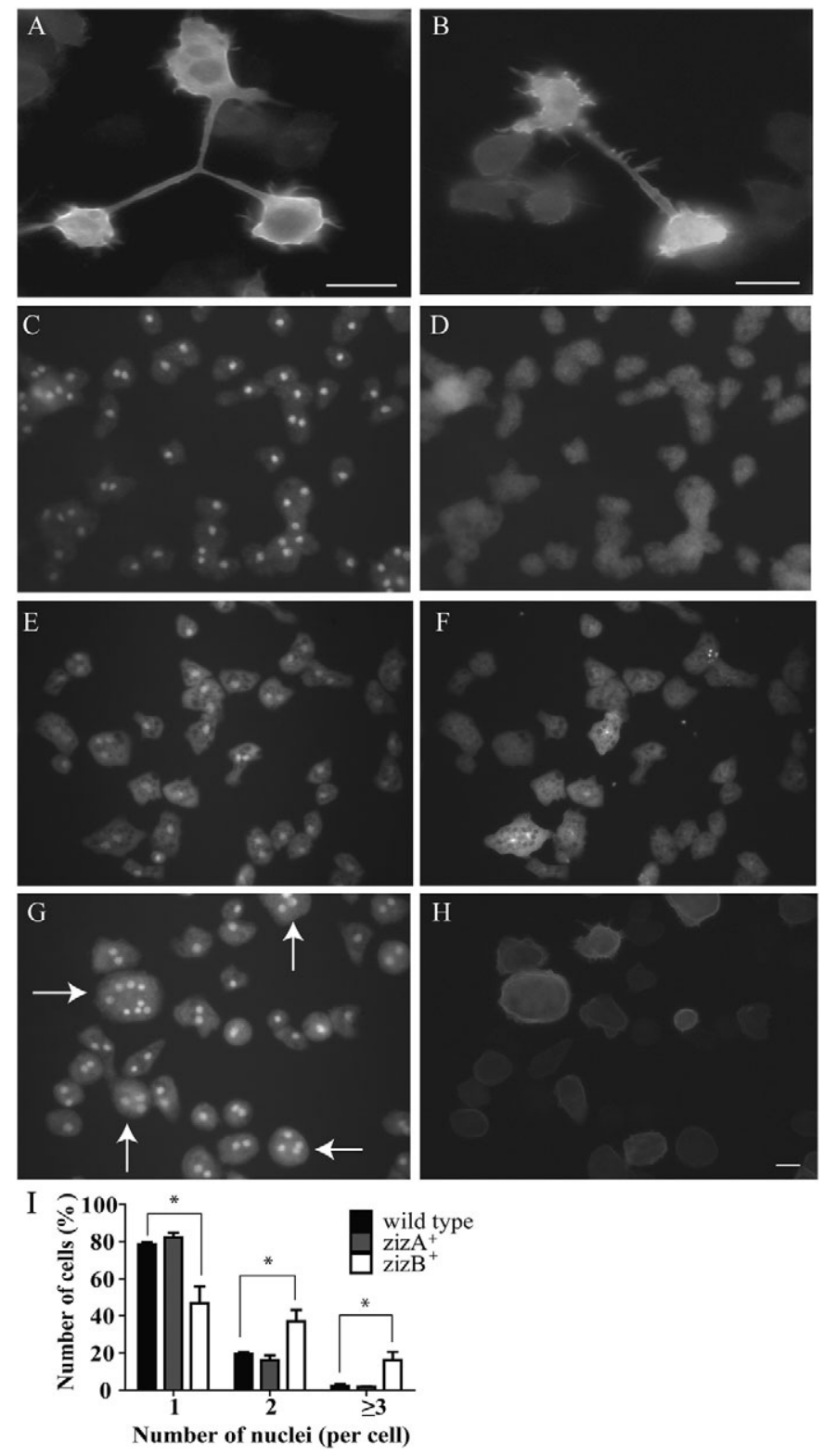

Fig. 7. ZizB overexpression mutants have a defect in cytokinesis.

(A,B) Live-cell images of $z i z B^{+}$cells illustrating a cytokinesis defect where (A) cells have failed to break the cytoplasmic bridge during repeated cell divisions or (B) the cleavage furrow begins to develop filopodia. Cells were cultivated in nutrient media for 5 days in shaking suspension before being fixed and stained with DAPI to investigate whether they were multinucleate. (C,E,G) DAPI-stained wild-type $\mathrm{Ax} 2, z i z A^{+}$and $z i z B^{+}$cells, respectively, where $z i z B^{+}$shows an increase in the number of multinucleate cells, indicated by the arrows (G). (D,F,H) Corresponding cells under $543 \mathrm{~nm}$ emission (GFP). (I) Histograms show the distribution of nuclei in wild-type Ax2, $z i z A^{+}$ and $z i z B^{+}$cells. There was a significant increase in the number of nuclei in the ziz $B^{+}$mutant. ${ }^{*} P<0.05$. Scale bars: $10 \mu \mathrm{m}$.

of all four genes was found to be constitutive throughout development (Fig. 2), rather than showing developmental regulation as seen in other $D$. discoideum GEF proteins such as the putative Rac GEF GxcDD (Mondal et al., 2007; Shaulsky et al., 1996) or Trix (Strehle et al., 2006). The expression patterns of the zizimin genes therefore suggest that their cellular roles are

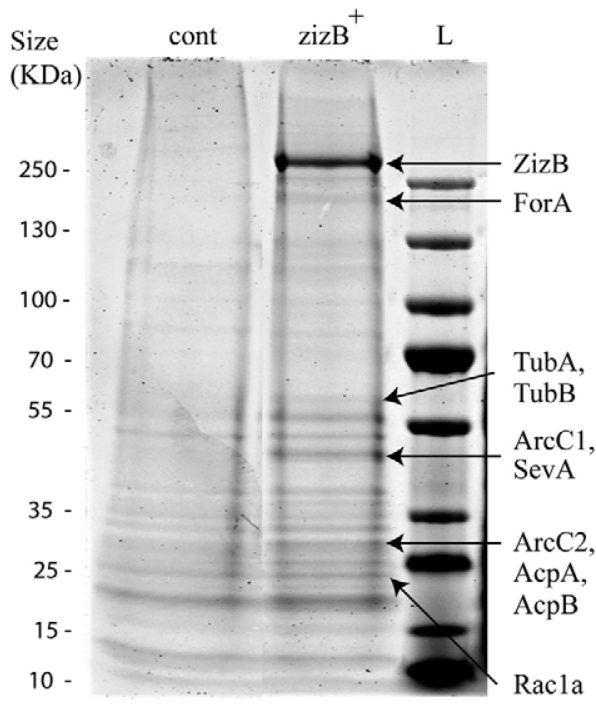

Fig. 8. Immunoprecipitation of ZizB-interacting proteins. (A) Extracts from wild-type (cont) or $z i z B^{+}$cells (containing ZizB-GFP) were used to identify specific binding partners. The purified complex was separated on a SDS gel and visualised with Coomassie Blue stain. Binding partners for ZizB (not found in extracts purified from wild-type cells) were ForA, TubA and TubB, ArpC1 and ArpC2, AcpA and AcpB and Rac1a. A complete list of binding partners is shown in supplementary material Table S1.

probably related to a potential role in cytoskeletal regulation during movement (rather than just development).

The analysis of the role of ZizA and ZizB proteins in development showed that cells lacking ZizA had no gross change in developmental phenotype (i.e. in fruiting body formation); however, loss of $\mathrm{ZizB}$ gave rise to aberrant fruiting body formation (Fig. 3). The lack of developmental changes following ZizA loss does not preclude an important role for the protein in development because the cellular roles for the protein might be, at least partially, compensated for by the other zizimin proteins. This functional redundancy has been shown in other small GTPase-related signalling families of $D$. discoideum Doc proteins (Para et al., 2009), RacB and Rac GEF1 (Park et al., 2004) and Trix Rac GEF (Strehle et al., 2006). However, ablation of ZizB did perturb development, suggesting a crucial role that cannot be replaced by related proteins, or that the relatively low expression levels of ZizA, ZizC and ZizD cannot effectively complement loss of ZizB.

\section{ZizB is involved in filopodia formation and cytokinesis}

Overexpression of ZizB-GFP identified a second role for the protein in controlling filopodia formation (Fig. 5). Increased filopodia formation (and microspike production) compared with the wild-type has also been shown following zizimin1 (p220) overexpression in fibroblasts, and this protein was shown to bind to the activated Rac enzyme Cdc42 (Lin et al., 2006). Furthermore, an increase in the number of filopodia has been shown following the overexpression of DocD in D. discoideum, which also binds Racla (Para et al., 2009). We showed a third role for $\mathrm{ZizB}$, where overexpression caused a large increase in cells unable to complete daughter cell separation as demonstrated by measuring the frequency of multinucleate cell formation following growth in shaking suspension in the absence of 
traction-mediated cell division (Fig. 7). Interestingly, a similar cytokinesis defect was found in the dynamin-A-null strain (Gopaldass et al., 2012; Wienke et al., 1999). This phenotype also suggests a role for $\mathrm{ZizB}$ in regulation of the actin-myosin cytoskeleton involved in cell division (Rivero et al., 2002; Rivero and Somesh, 2002). It is noteworthy that similar phenotypes (increased number of filopodia and cytokinesis defects) can be elicited by the overexpression of Racla (Dumontier et al., 2000). Combined with the fact that Racla was identified as a potential binding partner for $\mathrm{ZizB}$, our data strongly suggest that ZizB plays a role in activating Racla in filopodia formation, cytokinesis and chemotaxis (Rivero et al., 2002).

\section{Zizimin localisation}

Our current model for the function of Rac GEF proteins during chemotaxis is that, upon cAMP stimulation, these proteins are rapidly translocated to the cortex (or leading edge in chemotaxing cells) to initiate F-actin polymerisation through the regulation of Rac GTPases, enabling forward movement (Para et al., 2009). In contrast to this model, our data show that ZizB moves off the cortex into the cytosol following global cAMP stimulation, thus showing the opposite behaviour of previously described Rac GEF proteins such as DRG (Knetsch et al., 2001), DocD (Para et al., 2009) and Rac GEF1 (Park et al., 2004). One explanation for this movement would be a cortex-stabilising mechanism for ZizB, between cyclic periods of reorganisation caused by cAMP waves during chemotaxis. This is consistent with ZizB localisation at the front and side of the cell, with exclusion from the trailing edge or retracting pseudopods, during both random cell movement and in chemotaxis (Fig. 6). This localisation is distinct to proteins involved in initiating cell movement that are enriched at the leading edge (regulating and driving F-actin polymerisation) (Han et al., 2006). Cortical localisation might occur through DHR1 (phospholipid binding) activity, but domain-specific localisation studies are needed to confirm this.

\section{Zizimin B forms complexes with Rac1a and actin-binding proteins}

The binding partners for the $D$. discoideum zizimin proteins were previously unknown. In other model systems, the zizimin family of proteins is known to regulate the Rho family of small GTPases, which have a number of roles within the cell, including regulating the actin cytoskeleton during cell movement and other processes (Dumontier et al., 2000; Para et al., 2009; Rivero and Somesh, 2002). In relation to cell movement, dynamic regulation of F-actin polymerisation at the leading edge of the cell enables cytoskeleton reorganization, pseudopod formation and cell movement. Small GTPases play a key role in this process (Sasaki and Firtel, 2006). Here we demonstrate using coimmunoprecipitation that $\mathrm{ZizB}$ binds Racla, in addition to a number of actin- and myosin-associated proteins, within the natural environment of the cell. We further showed a direct binding of ZizB to Racla by binding of the bacterially expressed Racla protein, confirming this interaction in vitro, and in agreement with a role for ZizB in regulating the cytoskeleton (Fig. 8; supplementary material Table S1, Fig. S2). Direct binding has also been shown for the mammalian ZizB homologues (Dock7 and Dock8) with Rac1. This suggests that zizimin proteins have a crucial role in regulating Racl as a central small GTPase, which have been shown to promote filopodia and membrane ruffles in several model systems
(Ruusala and Aspenström, 2004; Watabe-Uchida et al., 2006a; Watabe-Uchida et al., 2006b). The binding, in vitro, of other less highly expressed Rac proteins identified here will need to be confirmed in further studies, because the low expression levels of these proteins might explain why only Racla was found in the direct co-immunoprecipitation reaction.

ZizB interacted with ARPC1 and ARPC2, two D. discoideum Arp2/3 subunits (Langridge and Kay, 2007). These subunits form the core of the Arp2/3 complex, which drives pseudopod formation and cell movement by catalysing nucleation of new actin filaments and thus overcoming the kinetic barrier to actin polymerisation (Insall and Machesky, 2009). The Arp2/3 complex represents one of many actin-modifying enzymes that accumulate at the leading edge driving pseudopod formation and cell movement (Sasaki and Firtel, 2006). Other ZizB binding partners identified here include ForA, Cap32, Cap34 and severin. ForA is a formin protein that functions as an actin filament nucleator. Knockout of ForA did not show any distinct phenotype for growth and development (Kitayama and Uyeda, 2003); however, another $D$. discoideum formin ForH (dDia2), has been implicated in filopodia formation, where the knockout mutant showed numerous defects in development, pseudopodia formation, filopodia formation and a decrease in cell motility and chemotaxis (Schirenbeck et al., 2005; Van Haastert and Bosgraaf, 2009). ForA could therefore be involved in filopodia formation by forming a complex with Rac1a and ZizB. Cap32 and Cap34 are subunits of the heterodimeric actin capping protein (Eddy et al., 1997). Capping proteins cap but do not sever (or nucleate) actin filaments and thereby prevent the addition or loss of actin subunits at the barbed filament end (Hug et al., 1995). Severin is a protein that severs the actin filament and remains bound to the barbed end (Eichinger et al., 1991). Both Cap32-Cap34 and severin play key roles in the regulation of the actin cytoskeleton, further supporting a role for ZizB in the dynamic regulation of the actin cytoskeleton.

Zizimin-related proteins are relatively poorly characterised members of the important Dock family of GEF proteins. In this paper, we examined the cellular function of ZizA and ZizB proteins in $D$. discoideum. We conclude that the $D$. discoideum ZizB has a significant role in development, and is necessary for normal cell movement and shape. We show that ZizB has an elevated association with the cortex (compared with the cytosol), and shows an unusual cortex delocalisation following global chemotactic stimulation. Furthermore, an elevated level of ZizB gives rise to an increase in the number of filopodia and partially interrupts cytokinesis. Finally, in agreement with these cellular functions (Dumontier et al., 2000), ZizB forms a complex with a number of cell cytoskeletal proteins, including Rac1a, and this is consistent with the role of mammalian zizimin proteins in preferentially binding Cdc42 and Rac small GTPases (Allen et al., 1998; Ruusala and Aspenström, 2004; Watabe-Uchida et al., 2006c). Our data therefore illustrate an important role for zizimin proteins in controlling development, cell shape and motility, filopodia formation and cytokinesis.

\section{Materials and Methods}

\section{Materials}

Axenic medium was purchased from ForMedium (Hunstanton, UK). All restriction enzymes, First Strand cDNA synthesis kit were purchased from Fermentas (St LeonRot, Germany). Nonidet P-40 (NP40), Trizma hydrochloride (Tris-HCl), sodium chloride $(\mathrm{NaCl})$, ethylene glycol tetraacetic acid (EGTA), ethylenediaminetetraacetic acid (EDTA), dithiothreitol (DTT), phenylmethanesulfonyl fluoride (PMSF), 
4',6-diamidino-2-phenylindole (DAPI), cyclic adenosine monophosphate (cAMP), potassium phosphate monobasic $\left(\mathrm{KH}_{2} \mathrm{PO}_{4}\right)$, potassium phosphate dibasic $\left(\mathrm{K}_{2} \mathrm{HPO}_{4}\right)$, methanol and caffeine were purchased from Sigma. The High Pure RNA isolation kit and the protease cocktail inhibitor was purchased from Roche (Welwyn Garden City, UK). Penicillin-streptomycin and blasticidin were purchased from PAA Laboratories (Yeovil, UK) and hygromycin from Invitrogen (Paisley, UK). The DNasefree kit was purchased from Ambion (Austin, TX). The anti-GFP antibody and the GFP trap agarose beads were purchased from ChromoTek (Planegg-Martinsried, Germany).

\section{Cell culture, strains and plasmids}

All $D$. discoideum strains were grown at $22^{\circ} \mathrm{C}$ in Axenic medium containing $100 \mu \mathrm{g} / \mathrm{ml}$ penicillin and $100 \mu \mathrm{g} / \mathrm{ml}$ streptomycin. A wild-type (Ax2) strain was used to generate all the mutants. Knockout constructs were created using methods as described previously (Terbach et al., 2011). Briefly, $5^{\prime}$ and $3^{\prime}$ fragments flanking the gene of interest were amplified by PCR (peqSTAR 96 Universal Gradient, Erlangen, Germany) from Ax2 genomic DNA. The 5' and $3^{\prime}$ PCR fragments were cloned into the pLPBLP expression vector (Faix et al., 2004) using the BamHI-PstI and the NcoI-KpnI restriction sites, respectively, incorporating the blasticidin resistance cassette. The knockout cassette was linearised and transformed into Ax2 wild-type cells by electroporation (Gene Pulser Xcell, Bio$\mathrm{Rad})$. Positive transformants were selected in nutrient medium containing blasticidin $(10 \mu \mathrm{g} / \mathrm{ml})$. Independent clones were screened for homologous integration by PCR, using a genomic and vector control, as well as a diagnostic knockout band. Loss of gene transcription was confirmed using reverse transcription PCR, where RNA was extracted from the independent positive transformants using the High Pure RNA isolation kit according to the manufacturer's instructions. Contaminating DNA was removed using the DNasefree kit prior to cDNA synthesis, using the First Strand cDNA synthesis kit and $1 \mu \mathrm{g}$ of RNA per sample. The cDNA was analysed by PCR to confirm loss of gene transcription. Primers were designed, where possible, to flank an intron, thus confirming cDNA amplification owing to the decrease in size of the cDNAderived product (in comparison to genomically derived product).

Overexpression constructs were prepared using full-length open reading frames of $z i z A$ and $z i z B$ that were amplified from cDNA with BamHI and NheI as flanking restriction sites. Endogenous BamHI sites were removed (silent mutations). The PCR products were cloned into a PCR ligation vector and sequences of the inserts were compared with the reference sequence on DictyBase. Correct clones were digested with Bam HI and NheI and ligated into the D. discoideum GFP and RFP expression vectors pDM450 and pDM451, respectively, under the control of Actin6 promoter (Veltman et al., 2009). Constructs were transformed into appropriate cell lines by electroporation and selected for using hygromycin $(50 \mu \mathrm{g} / \mathrm{ml})$. GFP or RFP overexpressor cell lines were confirmed by fluorescence microscopy and western blot analysis using antibodies against GFP or RFP.

\section{Development assays}

Filter assays were performed as described previously (Boeckeler et al., 2006; Williams et al., 2002). Briefly, cells were harvested in log-phase growth, washed in potassium phosphate buffer, and resuspended at a density of $1 \times 10^{7}$ cells $/ \mathrm{ml}$ and evenly distributed on a $47 \mathrm{~mm}$ nitrocellulose filter (Millipore, Watford, UK). The filter was incubated for 24 hours on an absorbent pad soaked in potassium phosphate buffer. Images were captured using a dissection microscope (MZ16 Leica Microsystems, Milton Keynes, UK) and a QImaging RetigaExi Fast1394 digital camera (QImaging, Surrey, Canada).

\section{Cell movement and image acquisition}

Chemotaxis assays were performed as described previously (Robery et al., 2011). In brief, cells were pulsed at a density of $1.7 \times 10^{6}$ cells $/ \mathrm{ml}$ with $30 \mathrm{nM}$ cAMP at 6 minute intervals for 5 hours before plating on coverslips. After cells had adhered, the coverslip was inverted onto a Dunn chamber (Hawksley, Lancing, UK) containing $5 \mu \mathrm{M}$ cAMP in the outer well. The response of the cells was recorded using time-lapse imaging and ImagePro 6.3 software (Media Cybernetics, Bethesda, MD) (one image every 6 seconds for 5 minutes). Experiments were repeated at least three times with an average of 20-30 cells quantified in each experiment. Computer-assisted analysis of cell movement and cell shape was performed using ImagePro 6.3 , measuring the velocity $(\mu \mathrm{m} / \mathrm{s})$ and the aspect. The aspect parameter is a measure of roundness, perfectly round cells have a value of 1 , whereas elongated cells have a value of $>1$. For fluorescence chemotaxis, aggregation-competent cells expressing either ZizA-GFP or ZizB-GFP were loaded into an Insall chemotaxis chamber (Muinonen-Martin et al., 2010). The phosphate buffer in the outer well was replaced with $1 \mu \mathrm{M}$ cAMP, and chemotaxing cells were visualised on a Nikon confocal microscope as above.

For localisation, cells containing fluorescently tagged GFP fusion proteins were cultivated in nutrient media, washed with potassium phosphate buffer and allowed to adhere to a glass coverslip before being visualised with an Olympus IX71 microscope (U-RFL-T laser, $543 \mathrm{~nm}$ emission, Olympus UPlanFL 60× oilimmersion objective with NA 1.25) with a QImaging RetigaExi Fast1394 digital camera and ImagePro6.3 software. To investigate cytokinesis defects, cells were cultured in a shaking suspension for 3 days and fixed with $100 \%$ methanol at $-20^{\circ} \mathrm{C}$ for 15 minutes before being fluorescently labelled with $4^{\prime}, 6$-diamidino-2phenylindole (DAPI) to visualise and count the number of nuclei per cell. All specimens were analysed using an Olympus IX71 microscope (U-RFL-T laser, $350 \mathrm{~nm}$ and $543 \mathrm{~nm}$ emission, respectively, Olympus UPlanFL $60 \times$ oil immersion objective with NA 1.25) with a QImaging RetigaExi Fast1394 digital camera. Data were processed using Adobe Photoshop or ImageJ software packages. To analyse the number of filopodia, time lapse images were taken every 5 seconds over a 10 minute period (Nikon Eclipse TE2000-E with a 1.4 NA Plan Apo $60 \times$ objective) using a QImaging RetigaEXi camera. To quantify the number of filopodia for wild-type, $z i z A^{+}$and $z i z B^{+}$cells an average of 27 individual cells were counted for three time points ( 0,5 and 10 minutes) over the 10 minute period. A filopodia is identified as a thin projection that extends from a pseudopod. The time-lapse movies were analysed and an average number of filopodia over the three time points was calculated for statistical analysis (unpaired, two-tailed Student's $t$-test). To show the colocalisation of the MTOC and ZizA, ZizA-RFP-containing cells were co-expressed with $\alpha$-tubulin-RFP (King et al., 2010) and visualised using live-cell fluorescent imaging with a Nikon A1R confocal microscope, $543 \mathrm{~nm}$ and $647 \mathrm{~nm}$ emission with a $1.4 \mathrm{NA}$ Plan Apo 60× objective using a QImaging RetigaEXi camera.

For global stimulation, aggregation-competent cells expressing either ZizAGFP or ZizB-GFP were loaded into a $\mu$-slide (Ibidi, Martinsried, Germany) and allowed to adhere to the surface. Cells were perfused with $200 \mu \mathrm{l}$ of $1 \mu \mathrm{M}$ cAMP and images were recorded on a Nikon A1R confocal microscope with a $1.4 \mathrm{NA}$ Plan Apo 60× objective.

\section{In vivo pull-down and purification of ZizA- and ZizB-interacting proteins and MS analyses}

Aggregation-competent cells were washed with potassium phosphate buffer (KK2; $16.5 \mathrm{mM} \mathrm{KH}_{2} \mathrm{PO}_{4}, 3.8 \mathrm{mM} \mathrm{K}_{2} \mathrm{HPO}_{4}, \mathrm{pH} 6.2$ ), resuspended at a density of $3 \times 10^{8}$ cells $/ \mathrm{ml}$ in potassium phosphate buffer, before being shaken for 20 minutes at 250 r.p.m. with $2.5 \mathrm{mM}$ caffeine. Cells were lysed $(0.5 \%$ NP40, $40 \mathrm{mM}$ Tris-HCl, pH 7.5, $20 \mathrm{mM} \mathrm{NaCl}, 5 \mathrm{mM}$ EGTA, $5 \mathrm{mM}$ EDTA, $10 \mathrm{mM}$ DTT, $1 \mathrm{mM}$ PMSF, $2 \times$ protease cocktail inhibitor). The cell lysate was incubated with GFP-Trap agarose beads as per the manufacturer's instructions. Briefly, the lysate was incubated with the GFP-Trap agarose beads at $4^{\circ} \mathrm{C}$ for 1 hour before being collected and washed with wash buffer (10 mM Tris- $\mathrm{HCl} \mathrm{pH} \mathrm{7.5,150} \mathrm{mM} \mathrm{NaCl,} 0.5 \mathrm{mM}$ EDTA, $1 \mathrm{mM}$ PMSF, $2 \times$ protease cocktail inhibitor). Immunocomplexes were dissociated from the beads by incubating at $95^{\circ} \mathrm{C}$ for 10 minutes before the beads were collected by centrifugation. The coimmunoprecipitated proteins were separated by SDS-PAGE (Invitrogen, Paisley, UK) and analysed by Coomassie Blue staining and mass spectrometry (MS) analysis.

GST pull-down assays were performed as described previously (Mondal et al., 2007). Briefly, GST-Rac proteins were expressed in E. coli and bound to glutathione-Sepharose beads (GE Healthcare). For the interaction of ZizA and ZizB with Rac proteins, $3 \times 10^{8} \mathrm{D}$. discoideum cells expressing ZizB-GFP were lysed in a lysis buffer [ $25 \mathrm{mM}$ Tris-HCl, $\mathrm{pH} 7.5,150 \mathrm{mM} \mathrm{NaCl}, 5 \mathrm{mM}$ EDTA, $0.5 \%$ Triton X-100, $1 \mathrm{mM} \mathrm{NaF}, 0.5 \mathrm{mM} \mathrm{Na}_{3} \mathrm{VO}_{4}, 1 \mathrm{mM}$ DTT, $1 \mathrm{mM}$ PMSF, $2 \times$ protease cocktail inhibitor (Roche)] and incubated with equal amounts of GSTRac-bound beads for 1 hour at $4^{\circ} \mathrm{C}$. Beads were washed with the wash buffer [25 mM Tris-HCl, pH 7.5, $150 \mathrm{mM} \mathrm{NaCl}, 5 \mathrm{mM}$ EDTA, $2 \times$ protease cocktail inhibitor (Roche)]. The eluate of the pull down was immnoblotted, the zizimin protein was detected using the GFP-specific monoclonal antibody (ChromoTek) and the Rac proteins were identified with a GST-specific monoclonal antibody (Millipore Calbiochem OB03). Cells expressing only GST were used as a control. The immunoblot was visualised using the Odyssey Sa infrared imaging system.

\section{Funding}

This work was supported by an NC3Rs grant [grant number G0900775] to R.S.B.W.; by the SouthWest London Academic Network (SWan); and a Brain travel grant to N.K.P. Deposited in PMC for immediate release.

Supplementary material available online at

http://jcs.biologists.org/lookup/suppl/doi:10.1242/jcs.100966/-/DC1

\section{References}

Allen, W. E., Zicha, D., Ridley, A. J. and Jones, G. E. (1998). A role for Cdc42 in macrophage chemotaxis. J. Cell Biol. 141, 1147-1157.

Boeckeler, K., Adley, K., Xu, X., Jenkins, A., Jin, T. and Williams, R. S. (2006). The neuroprotective agent, valproic acid, regulates the mitogen-activated protein kinase pathway through modulation of protein kinase A signalling in Dictyostelium discoideum. Eur. J. Cell Biol. 85, 1047-1057.

Brugnera, E., Haney, L., Grimsley, C., Lu, M., Walk, S. F., Tosello-Trampont, A. C., Macara, I. G., Madhani, H., Fink, G. R. and Ravichandran, K. S. (2002). 
Unconventional Rac-GEF activity is mediated through the Dock180-ELMO complex. Nat. Cell Biol. 4, 574-582.

Côté, J. F. and Vuori, K. (2002). Identification of an evolutionarily conserved superfamily of DOCK180-related proteins with guanine nucleotide exchange activity. J. Cell Sci. 115, 4901-4913.

Côté, J. F. and Vuori, K. (2006). In vitro guanine nucleotide exchange activity of DHR2/DOCKER/CZH2 domains. Methods Enzymol. 406, 41-57.

Côté, J. F., Motoyama, A. B., Bush, J. A. and Vuori, K. (2005). A novel and evolutionarily conserved PtdIns(3,4,5)P3-binding domain is necessary for DOCK180 signalling. Nat. Cell Biol. 7, 797-807.

Dumontier, M., Höcht, P., Mintert, U. and Faix, J. (2000). Rac1 GTPases control filopodia formation, cell motility, endocytosis, cytokinesis and development in Dictyostelium. J. Cell Sci. 113, 2253-2265.

Eddy, R. J., Han, J. and Condeelis, J. S. (1997). Capping protein terminates but does not initiate chemoattractant-induced actin assembly in Dictyostelium. J. Cell Biol. 139, 1243-1253.

Eichinger, L., Noegel, A. A. and Schleicher, M. (1991). Domain structure in actinbinding proteins: expression and functional characterization of truncated severin. $J$. Cell Biol. 112, 665-676.

Engelhardt, K. R., McGhee, S., Winkler, S., Sassi, A., Woellner, C., Lopez-Herrera, G., Chen, A., Kim, H. S., Lloret, M. G., Schulze, I. et al. (2009). Large deletions and point mutations involving the dedicator of cytokinesis 8 (DOCK8) in the autosomal-recessive form of hyper-IgE syndrome. J. Allergy Clin. Immunol. 124, 1289-1302, e4

Faix, J., Kreppel, L., Shaulsky, G., Schleicher, M. and Kimmel, A. R. (2004). A rapid and efficient method to generate multiple gene disruptions in Dictyostelium discoideum using a single selectable marker and the Cre-loxP system. Nucleic Acids Res. 32, e143.

Gopaldass, N., Patel, D., Kratzke, R., Dieckmann, R., Hausherr, S., Hagedorn, M., Monroy, R., Krüger, J., Neuhaus, E. M., Hoffmann, E. et al. (2012). Dynamin A, Myosin IB and Abpl couple phagosome maturation to F-actin binding. Traffic 13 120-130.

Han, J. W., Leeper, L., Rivero, F. and Chung, C. Y. (2006). Role of RacC for the regulation of WASP and phosphatidylinositol 3-kinase during chemotaxis of Dictyostelium. J. Biol. Chem. 281, 35224-35234.

Hug, C., Jay, P. Y., Reddy, I., McNally, J. G., Bridgman, P. C., Elson, E. L. and Cooper, J. A. (1995). Capping protein levels influence actin assembly and cell motility in Dictyostelium. Cell 81, 591-600.

Insall, R. H. and Machesky, L. M. (2009). Actin dynamics at the leading edge: from simple machinery to complex networks. Dev. Cell 17, 310-322.

Jaffe, A. B. and Hall, A. (2005). Rho GTPases: biochemistry and biology. Annu. Rev. Cell Dev. Biol. 21, 247-269.

King, J. S., Veltman, D. M., Georgiou, M., Baum, B. and Insall, R. H. (2010). SCAR WAVE is activated at mitosis and drives myosin-independent cytokinesis. J. Cell Sci. 123, 2246-2255.

Kitayama, C. and Uyeda, T. Q. (2003). ForC, a novel type of formin family protein lacking an FH1 domain, is involved in multicellular development in Dictyostelium discoideum. J. Cell Sci. 116, 711-723.

Kölsch, V., Charest, P. G. and Firtel, R. A. (2008). The regulation of cell motility and chemotaxis by phospholipid signaling. J. Cell Sci. 121, 551-559.

Knetsch, M. L., Schäfers, N., Horstmann, H. and Manstein, D. J. (2001). The Dictyostelium Bcr/Abr-related protein DRG regulates both Rac- and Rab-dependent pathways. EMBO J. 20, 1620-1629.

Kobayashi, S., Shirai, T., Kiyokawa, E., Mochizuki, N., Matsuda, M. and Fukui, Y. (2001). Membrane recruitment of DOCK180 by binding to PtdIns(3,4,5)P3. Biochem J. 354, 73-78.

Langridge, P. D. and Kay, R. R. (2007). Mutants in the Dictyostelium Arp2/3 complex and chemoattractant-induced actin polymerization. Exp. Cell Res. 313, 2563-2574.

Lin, Q., Yang, W., Baird, D., Feng, Q. and Cerione, R. A. (2006). Identification of a DOCK180-related guanine nucleotide exchange factor that is capable of mediating a positive feedback activation of Cdc42. J. Biol. Chem. 281, 35253-35262.

Loomis, W. F. and Shaulsky, G. (2011). Developmental changes in transcriptional profiles. Dev. Growth Differ. 53, 567-575.

Meller, N., Irani-Tehrani, M., Kiosses, W. B., Del Pozo, M. A. and Schwartz, M. A. (2002). Zizimin1, a novel Cdc42 activator, reveals a new GEF domain for Rho proteins. Nat. Cell Biol. 4, 639-647.

Meller, N., Merlot, S. and Guda, C. (2005). CZH proteins: a new family of Rho-GEFs. J. Cell Sci. 118, 4937-4946.

Mondal, S., Neelamegan, D., Rivero, F. and Noegel, A. A. (2007). GxcDD, a putative RacGEF, is involved in Dictyostelium development. BMC Cell Biol. 8, 23.

Muinonen-Martin, A. J., Veltman, D. M., Kalna, G. and Insall, R. H. (2010). An improved chamber for direct visualisation of chemotaxis. PLOS ONE 5, e15309.
Para, A., Krischke, M., Merlot, S., Shen, Z., Oberholzer, M., Lee, S., Briggs, S. and Firtel, R. A. (2009). Dictyostelium Dock180-related RacGEFs regulate the actin cytoskeleton during cell motility. Mol. Biol. Cell 20, 699-707.

Parikh, A., Miranda, E. R., Katoh-Kurasawa, M., Fuller, D., Rot, G., Zagar, L., Curk, T., Sucgang, R., Chen, R., Zupan, B. et al. (2010). Conserved developmental transcriptomes in evolutionarily divergent species. Genome Biol. 11, R35.

Park, K. C., Rivero, F., Meili, R., Lee, S., Apone, F. and Firtel, R. A. (2004). Rac regulation of chemotaxis and morphogenesis in Dictyostelium. EMBO J. 23, 4177 4189.

Rivero, F. and Somesh, B. P. (2002). Signal transduction pathways regulated by Rho GTPases in Dictyostelium. J. Muscle Res. Cell Motil. 23, 737-749.

Rivero, F., Illenberger, D., Somesh, B. P., Dislich, H., Adam, N. and Meyer, A. K. (2002). Defects in cytokinesis, actin reorganization and the contractile vacuole in ells deficient in RhoGDI. EMBO J. 21, 4539-4549.

Robery, S., Mukanowa, J., Percie du Sert, N., Andrews, P. L. and Williams, R. S. (2011). Investigating the effect of emetic compounds on chemotaxis in Dictyostelium identifies a non-sentient model for bitter and hot tastant research. PLOS ONE 6 , e24439.

Rot, G., Parikh, A., Curk, T., Kuspa, A., Shaulsky, G. and Zupan, B. (2009) dictyExpress: a Dictyostelium discoideum gene expression database with an explorative data analysis web-based interface. BMC Bioinformatics 10, 265.

Ruusala, A. and Aspenström, P. (2004). Isolation and characterisation of DOCK8, a member of the DOCK180-related regulators of cell morphology. FEBS Lett. 572, 159-166.

Sasaki, A. T. and Firtel, R. A. (2006). Regulation of chemotaxis by the orchestrated activation of Ras, PI3K, and TOR. Eur. J. Cell Biol. 85, 873-895.

Schaap, P. and Wang, M. (1986). Interactions between adenosine and oscillatory cAMP signaling regulate size and pattern in Dictyostelium. Cell 45, 137-144.

Schirenbeck, A., Arasada, R., Bretschneider, T., Schleicher, M. and Faix, J. (2005) Formins and VASPs may co-operate in the formation of filopodia. Biochem. Soc. Trans. 33, 1256-1259.

Schleicher, M., Gerisch, G. and Isenberg, G. (1984). New actin-binding proteins from Dictyostelium discoideum. EMBO J. 3, 2095-2100.

Shaulsky, G., Escalante, R. and Loomis, W. F. (1996). Developmental signal transduction pathways uncovered by genetic suppressors. Proc. Natl. Acad. Sci. USA 93, 15260-15265.

Strehle, A., Schleicher, M. and Faix, J. (2006). Trix, a novel Rac guanine-nucleotide exchange factor from Dictyostelium discoideum is an actin-binding protein and accumulates at endosomes. Eur. J. Cell Biol. 85, 1035-1045.

Takahashi, K., Kohno, T., Ajima, R., Sasaki, H., Minna, J. D., Fujiwara, T., Tanaka, N. and Yokota, J. (2006). Homozygous deletion and reduced expression of the DOCK8 gene in human lung cancer. Int. J. Oncol. 28, 321-328.

Terbach, N., Shah, R., Kelemen, R., Klein, P. S., Gordienko, D., Brown, N. A. Wilkinson, C. J. and Williams, R. S. (2011). Identifying an uptake mechanism for the antiepileptic and bipolar disorder treatment valproic acid using the simple biomedical model Dictyostelium. J. Cell Sci. 124, 2267-2276.

Triviños-Lagos, L., Ohmachi, T., Albrightson, C., Burns, R. G., Ennis, H. L. and Chisholm, R. L. (1993). The highly divergent alpha- and beta-tubulins from Dictyostelium discoideum are encoded by single genes. J. Cell Sci. 105, 903-911.

Van Haastert, P. J. and Bosgraaf, L. (2009). The local cell curvature guides pseudopodia towards chemoattractants. HFSP J. 3, 282-286.

Veltman, D. M., Akar, G., Bosgraaf, L. and Van Haastert, P. J. (2009). A new set of small, extrachromosomal expression vectors for Dictyostelium discoideum. Plasmid 61, 110-118.

Watabe-Uchida, M., Govek, E. E. and Van Aelst, L. (2006a). Regulators of Rho GTPases in neuronal development. J. Neurosci. 26, 10633-10635.

Watabe-Uchida, M., John, K. A., Janas, J. A., Newey, S. E. and Van Aelst, L. (2006b). The Rac activator DOCK7 regulates neuronal polarity through local phosphorylation of stathmin/Op18. Neuron 51, 727-739.

Watabe-Uchida, M., John, K. A., Janas, J. A., Newey, S. E. and Van Aelst, L. (2006c). The Rac activator DOCK7 regulates neuronal polarity through local phosphorylation of stathmin/Op18. Neuron 51, 727-739.

Wienke, D. C., Knetsch, M. L., Neuhaus, E. M., Reedy, M. C. and Manstein, D. J. (1999). Disruption of a dynamin homologue affects endocytosis, organelle morphology, and cytokinesis in Dictyostelium discoideum. Mol. Biol. Cell 10, 225243.

Williams, R. S., Cheng, L., Mudge, A. W. and Harwood, A. J. (2002). A common mechanism of action for three mood-stabilizing drugs. Nature 417, 292-295.

Zhang, Q., Davis, J. C., Lamborn, I. T., Freeman, A. F., Jing, H., Favreau, A. J Matthews, H. F., Davis, J., Turner, M. L., Uzel, G. et al. (2009). Combined immunodeficiency associated with DOCK8 mutations. N. Engl. J. Med. 361, 2046-2055.

Zigmond, S. H., Joyce, M., Borleis, J., Bokoch, G. M. and Devreotes, P. N. (1997) Regulation of actin polymerization in cell-free systems by GTPgammaS and Cdc42. J. Cell Biol. 138, 363-374. 